\title{
Design and performance study of clutch disc assembly of wide-angle and large-hysteresis multi- stage damper
}

\section{Maoqing Xie}

Jiangsu University

Leigang Wang ( $\square$ lgwang@mail.ujs.edu.cn )

Jiangsu University https://orcid.org/0000-0002-9154-2571

\section{Yao Huang}

Jiangsu University

\section{Original Article}

Keywords: Clutch, Noise, Vibration, Wide angle, Low stiffness, Great hysteresis, Multistage damper

Posted Date: November 18th, 2020

DOI: https://doi.org/10.21203/rs.3.rs-110239/v1

License: (c) (1) This work is licensed under a Creative Commons Attribution 4.0 International License.

Read Full License 


\section{Abstract}

The clutch is an important component of the automobile driveline system, and its function is to ensure stable starting, smooth shifting and easy operation of the automobile. Judder and tremble are two kinds of common vibrations when a car starts, which seriously affect the driving and riding feelings of people in the car. Starting vibration and shaking are two kinds of common vibration in the beginning of a car, which seriously affect the driving and riding experience of people in the car. These two kinds of starting vibrations are closely related to the dry friction clutch in the driveline system, and the multi-stage torsional damper located on the clutch disc assembly plays an important role in the torsional characteristics of the vehicle driveline system. The stability of transmitted torque in automobile driveline system is directly affected by clutch torsional performance. In order to effectively eliminate torsional vibration and noise of driveline system excited by engine and improve driving comfort, this paper studies the structure and functional principle of wide-angle and large-hysteresis multistage damper disc assembly, and puts forward wide-angle and low-stiffness damping technology, large-hysteresis clutch technology, new splittype pre-damping structure technology, component protection buffer damping structure technology and multistage damping structure technology, and puts forward systematic solutions to effectively reduce driveline system vibration and noise.

\section{Introduction}

China's automobile production is increasing continuously, the number of automobiles is increasing, and the demand of export market is expanding, which actively promotes the development of China's automobile clutch industry. Especially, the development of DCT technology in China will give our country's dry friction clutch industry a new development opportunity. In recent years, Noise, vibration and harshness $(\mathrm{NVH})$ of automobile has become a rigid index for evaluating automobile performance [1], and they are also one of the main considerations when people choose a vehicle.

Automobile transmission system has the characteristics of strong nonlinearity and weak damping, and it is easy to produce vibration or noise under the conditions of engine or uneven road. When these vibrations and noises are transmitted to chassis and body, the driving and riding comfort will be deteriorated.

Torsional vibration in automobile transmission system will increase the load of transmission system components, such as shaft, bearing, gear, shell, etc., enhance the noise inside the car, and reduce the driving comfort of automobile. Because it is difficult to avoid the vibration of automobile transmission system, a torsional damper is usually installed on the clutch driven plate assembly. Its elastic element can reduce the torsional stiffness of the transmission system, thus reducing the natural frequency and transferring the resonance out of the common speed range of the engine [2].

Foreign scholars started early and studied deeply the nonlinear characteristics of clutch and torsion of automobile transmission system. Especially, in the aspect of starting jitter, there have been detailed 
researches on mechanism analysis, transmission system simulation and related tests, but few studies have been made on the phenomena of vehicle bumping and running away caused by clutch.

PRASAD et al. [3] reduced the fluctuation amplitude of transmission system torsion by optimizing the damping torque of torsion damper, thus reducing the gear knocking noise under the driving working condition of vehicle; TSUJIUCHI et al. [4], aiming at the problem of gear knocking at idle speed, analyzes the influence of the hysteresis torque of the first stage of torsional damper on the knocking strength, and finally selects the optimal hysteresis torque through the simulation results; BHAGATE et al. [5] based on establishing the torsional vibration model of the vehicle transmission system to reduce the torsional fluctuation amplitude and gear striking strength of the transmission system, the optimal torsional stiffness and retarding torque of the shock absorber are selected by design of experiment; GREGORI [6] set up a clutch performance test bench, through which the specific values of negative gradient of friction coefficient and relative sliding speed can be measured, and it is found that the attenuation effect of friction facing made of different materials on judder is obviously different. In this paper, the judgment standard of starting jitter with the maximum longitudinal acceleration of the car body is put forward. WICKRAMARACHI et al. [7], in order to study the mechanism of noise caused by clutch self-excited vibration, established a six-degree-of-freedom model of the transmission system considering the axial nonlinear characteristics of the pressure plate, and analyzed the influence of the axial stiffness of the cushion plate and the size of the pressure plate on the stability of the established transmission system.

Domestic scholars started late in the research on the nonlinear characteristics of clutch and the torsion of transmission system. At present, enterprises and universities have carried out simulation and experimental research on starting jitter, and some specific problems in engineering practice have been solved by their research results, but no laws with certain reference value have been summarized, and no complete system has been formed.

Y H Chen [8] of South China University of Technology has studied the test and evaluation methods of starting jitter. By combining the subjective evaluation of passengers with the objective test data evaluation, auto start jitter is divided into ten grades according to the severity; S Tao et al. [9] established a four-degree-of-freedom model including friction clutch, characterized the friction nonlinear characteristics of clutch by KARNOPP model, and analyzed the influence of clutch parameters on starting jitter, but did not consider the attenuation effect of clutch torsional damper in the modeling.

G Q Wu of TONGJI University $[10,11,12]$ and others respectively simulated the starting process of automatic mechanical transmission, dual clutch transmission and automatic transmission vehicles, and analyzed the influence of engine throttle opening and engagement time on clutch transmission torque and starting impact. H W Wu et al. [13] designed and developed a new torsional damper with three-level stiffness to solve the serious gear knock problem of transmission under the condition of vehicle crawling, and verified the performance of the torsional damper with three-level stiffness through special bench test and real vehicle test. X L Liu et al. [14] proposed to establish a four-degree-of-freedom lumped parameter 
model of the transmission system at idle speed, and gave the calculation method of the dynamic response of the system at idle speed.

In the aspect of theoretical research, the traditional Holtz method, energy method and amplification factor method are transplanted to the computer to handle the torsion calculation of complex systems. The dynamic model built by people has developed from the initial simple model with three degrees of freedom to the torsional vibration analysis model with multiple degrees of freedom, which is closer to the actual system. The considered excitation has also developed from a single deterministic excitation in the past to multiple deterministic and stochastic excitations now $[15,16]$.

In order to effectively eliminate the vibration caused by resonance in the automobile transmission system because the frequency of the engine excitation vibration source is the same as the natural frequency of the transmission system, reduce the transmission of the clutch to the pulsating torsional vibration of the engine, and reduce the vibration, abnormal noise and harsh noise caused by the transmission parts such as the transmission and differential during idling and acceleration, so as to improve the driving and riding comfort. In view of the above problems, this paper puts forward the key technical problems that need to be solved in the traditional clutch driven plate assembly: (1) to realize wide-angle and low-stiffness vibration reduction without increasing the specifications and torque transmission capacity of the shock absorber; (2) The service life of the clutch is guaranteed, and at the same time, large damping vibration reduction is realized; (3) Solve the shortcomings of the traditional split pre-vibration damping structure, such as complex structure, many parts, difficult assembly, low efficiency and high manufacturing cost, optimize the design of split pre-vibration damping structure, improve production efficiency and reduce manufacturing cost; (4) Optimize the design of vibration reduction structure to reduce the impact damage of engine to clutch components; (5) Under the condition of not increasing the specifications of shock absorber, multi-stage vibration reduction can be realized to meet the NVH requirements of engine and whole vehicle under different working conditions. Therefore, combined with the development trend and market demand of automobile clutch technology at home and abroad, this paper solves the key technical problems of automobile noise and vibration by developing the technology of wide-angle and largedamping multi-stage damping clutch driven plate assembly.

\section{Structure And Working Principle Of Torsional Damper Of Traditional Clutch Disc Assembly}

The structure of the traditional clutch driven disc assembly is shown in Figure 1, which is mainly composed of friction facing, driven plate, retain plate, spring, disc hub and other parts. The engine power is transferred to the clutch cover assembly through the flywheel. The cover assembly transfers the power to the driven plate 6 and retain plate 7 through the friction facing 1, and then to the disc hub 15 through the spring 17 and 18 for vibration damping, which is transferred to the disc hub 15 through the spline to the gearbox input shaft. The torsional damper structure of traditional clutch disc assembly is mainly composed of pre- damping system and main damping system. 
1) The structure of idle vibration reduction system is shown in Figure 2:

Idle speed damping system is mainly composed of positioning ring (II) 8, Belleville washer (I) 9 , positioning ring (III) 10 , Belleville washer (II) 11 , positioning ring (I) 12 , spring seat (I) 13 , spring (III) 14 , disc hub (I) 15 and other parts. The amount of idling damping torque depends on the number and stiffness of the springs. From an engineering point of view, the springs must be arranged symmetrically, so there are four kinds of springs that can be installed $-2,3,4$ or 6 . Through the combination of two kinds of springs with different stiffness, there are 12 choices of idle vibration damping stiffness, and the coverage can reach $0.5-9 \mathrm{~N}$.m per degree. It can fully meet the requirements of idling vibration damping stiffness of automobiles at present. When the inner hub (I)15 and the outer hub (II) 16 rotate to the extreme position relatively in Figure 1, the mating spline sides of the two are in contact, and the clutch enters the main damping working state.

2)The structure of the main vibration reduction system is shown in Figure 3 :

The main damping system is mainly composed of stop pin 5 , driven plate 6 , retain plate 7 , positioning ring (II) 8, Belleville washer (I) 9, positioning ring (I) 12, disc hub (II) 16, spring (I) 17, spring (II) 18 and other components. When the driven disc and the damping disc rotate relatively for a certain angle, the side edge of the slightly wider driven disc window starts to contact with the second-stage damping spring, and all the damping springs work together to buffer the impact during clutch engagement and power transmission. In the process of relative rotation between driven disc and damping disc, due to the action of the disc spring, the damping washer generates a certain friction damping torque with driven disc and damping disc for damping vibration. The stiffness and torque of the main damping system mainly depend on the stiffness and limit load of the main damping spring. Its design is based on the matching requirements of the whole vehicle transmission system. Main damping springs with different stiffness and ultimate load have been designed into standard series with the same overall dimensions. Due to the limit stress of the material, some springs cannot work in the compressed state. At this time, the stop pin 5 will contact with the corresponding notch side of the hub 16 , which will protect the main damping spring to a certain extent.

\section{The Structure Design And Principle Of The Disc Assembly Of The New Wide-angle Large Hysteresis Multi-stage Damper}

Therefore, the way to improve the NVH characteristics of the whole vehicle through the clutch is to adjust the structure of the driven disc and change its performance parameters. Clutch driven disc assembly is mainly composed of friction plate, elastic elements and damping elements, and its main performance parameters include friction coefficient $f$, torque $T$ (torque transmission capacity), torsional stiffness $K$, torsional angle $\theta$ and damping value $H$, etc. the relationship among them is: $T=K \theta+H=\beta T e$, where $T e$ is the maximum output torque of the engine, which is an inherent characteristic of the engine and a constant value; $\beta$ is the backup coefficient of clutch, which is a constant. Generally, the value of $\beta$ for passenger vehicles is 1.3 and that for commercial vehicles is 1.6. 
$\mathrm{J}$ L Bi et al. [17] analyzed the torsional mode and sensitivity of power transmission system, and concluded that the torsional stiffness $K$ and damping value $H$ of clutch are two important performance parameters that determine the vibration reduction function of driven plate: the smaller the torsional stiffness, the smaller the resonance peak value and the smaller the resonance frequency; The larger the damping value is, the smaller the resonance peak value is, and the resonance frequency has no obvious change. Therefore, in order to attenuate the vibration transmitted by the engine as soon as possible, the torsional stiffness of the clutch driven plate should be as small as possible, and the damping value should be as large as possible. However, due to the limitation of the structure and space of the driven disc, the torsion angle $\theta$ cannot be too large and usually does not exceed 14 .

Under this limitation, if the torsion is just too small, the effective torque $K \theta$ transmitted by the clutch will be too small, and the transmission efficiency of the clutch will be too low. When designing the clutch, it is generally required that $K \theta=(85 \sim 93) \% \beta T e$. According to the relationship between the performance parameters of the driven disc mentioned above, if the damping value is too large, the clutch will also be affected. Moreover, the larger the damping value, the slower the response of mechanical transmission, and the excessive damping value will also affect the sensitivity of automobile operation. To sum up, properly increasing the torsional angle (wide angle) to reduce the torsional stiffness and properly increasing the damping value can improve the $\mathrm{NVH}$ characteristics of the whole vehicle. Therefore, this paper proposes to research and develop a wide-angle and large-damping multi-stage damping clutch driven disc assembly.

The driven plate assembly of the wide-angle multi-stage damping clutch is mainly composed of front retain plate, rear retain plate, hub plate, damping spring, cushion plate, rear damping plate, front hysteresis plate and Belleville washer. The product structure is shown in Figure 4, and the real product is shown in Figure 5.

The main technical innovations of the driven disc assembly of the wide-angle large damping multi-stage damping clutch are as follows:

1) Wide-angle and low-stiffness vibration reduction technology

By increasing the torsional damping angle of the clutch without increasing the specifications and torque transmission capacity of the damper, the purpose of reducing the spring stiffness can be achieved, and then the clutch can obtain better damping performance. In view of the defect that the main damping part of the traditional clutch is limited by the stop pin (double-headed rivet) hitting the hub (as shown in Figure 6), and its rotation angle can't be enlarged due to the space limitation (generally, the rotation angle is about 7-15 degrees), it is proposed to bend the outer side of the front damping disc and change the impact limiting parts from the brake pin to the damping disc (as shown in Figure 7) 
The forward torsion angle of the traditional clutch is generally 15-21 and the reverse torsion angle is generally 10-15 (as shown in Figure 8). The forward torsion angle can reach 42, and the reverse torsion angle can reach 28 (as shown in Figure 9), and the damping effect is improved by more than 1.5 times compared with that of the common clutch, and the vibration isolation rate can reach more than $65 \%$ in the engine 800rpm-4500rpm range.

2) large hysteresis vibration reduction structure technology

The torque fluctuation of the engine is consumed by increasing the clutch damping value, so as to reduce the transmission of the clutch to the pulsating torsional vibration of the engine, reduce the jitter, knocking noise and harsh noise caused by vibration in all rotating speed ranges of transmission parts such as transmission and differential during idling, acceleration and normal driving, and improve the ride comfort and shift smoothness.

The main hysteresis value of large hysteresis clutch is $25-35 \mathrm{~N} . \mathrm{m}$, while that of traditional clutch is generally $8-15 \mathrm{n} . \mathrm{m}$. The Muller-BBM automobile torsional vibration/noise First Axle analysis system (as shown in Figure 10) is used for NVH test in a self-owned brand vehicle. The experimental results show that increasing the damping value of clutch driven plate can reduce the amplitude of the system and improve the NVH problem during vehicle acceleration (as shown in Figure 11)

3) New split type pre-damping structure technology

By taking advantage of the characteristic that the injection molding process is easy to realize the complex modeling of the workpiece, a new split-type pre-vibration damping structure (as shown in Figure 12) technology is proposed, which is improved on the traditional damping plate, so that it has the function of damping plate and clamping disc, and solves the shortcomings of the traditional split-type pre-vibration damping structure, such as complex structure, many parts, difficult assembly, low efficiency and high manufacturing cost. The application of the new split pre-damping structure technology can improve the production efficiency by more than $150 \%$ and reduce the manufacturing cost by more than $30 \%$.

4) component protection buffer damping structure technology

By adding rubber buffer spring in the traditional clutch damping spring, the buffer spring is developed to absorb vibration and reduce noise when impact occurs, and protect the internal parts of the clutch so as to improve the service life of the clutch driven plate assembly.

The traditional shock absorber uses the damping spring in the shock absorber for damping and buffering, but it is completely borne by the clutch stop pin (limit rivet) when it is impacted greatly. Although it has certain damping and buffering capacity, the service life of the clutch is still affected to some extent. Adopting clutch component protection, buffer and vibration reduction structure technology, two special rubber springs are installed in a symmetrical set of main vibration reduction springs, which can absorb vibration and reduce noise when the clutch is impacted, and protect the internal components of the clutch 
to improve the service life of the clutch driven plate assembly. Its working principle is: after the rubber spring is installed in the damping spring, it can be seen from the clutch characteristic curve (as shown in Figure 13) that the rear section of the torsional damping characteristic curve of the clutch is an increasing curve, which is caused by the clutch torque capacity increasing when the rubber spring plays a buffering role and absorbs the impact caused by engine torque fluctuation. When driving on a flat road, the rubber spring does not work and its torque transmission capacity remains unchanged. When the engine torque fluctuates sharply on the harsh environment, the rubber spring starts to work, and its torque capacity increases by $15 \%$ instantly, thus protecting the internal components of the clutch and prolonging the fatigue service life of the clutch.

5) Multi-stage vibration reduction technology

The output power and torque of vehicle engines under different working conditions (such as idling, starting, accelerating, driving at a constant speed, etc.) have different characteristics. the traditional clutch generally only has 1-2 stages of vibration reduction (as shown in fig. 8), which can only meet the vibration reduction requirements under 1-2 working conditions. Multi-stage vibration reduction technology, innovative use of a variety of different types and stiffness of vibration spring combinations, to achieve the combination of clutch main vibration reduction and pre-vibration reduction of 3-6 stages of multi-stage vibration reduction, effectively meet the vibration reduction requirements of vehicles under various working conditions.

It can be seen from the clutch characteristic curve (as shown in fig. 8) that the main damping and predamping of the traditional clutch generally have only one stage each, which can't meet the damping requirements under different torques. the 200 series products transformed by this technology innovatively adopt the arc spring damping spring structure (as shown in fig. 12), and realize the two-stage predamping through the asymmetric design of the pre-damping disc hub, i.e. the first stage (forward 0-3, reverse 0-3) Level 2 (3-22 in the forward direction and 0-3 in the reverse direction) participates in vibration reduction and torque transmission at start-up (slightly larger output power and torque). In the main damping part, a group of rubber springs are added into the original damping springs, whose length is much smaller than that of the damping springs. When the clutch transmits torque to force the damping springs to compress to a certain length, the rubber springs start to work, absorbing the impact generated by engine torque fluctuation and transmitting torque. The main damping part (forward 22-42, anyway 828 ) is divided into two stages: the first stage (forward 22-38, reverse 8-24) participates in the vibration reduction when the vehicle runs at a constant speed (the output power and torsion are relatively stable, and the torque waveform is small); Level 2 (38-42 in the forward direction and 24-28 in the reverse direction) participates in vibration reduction and torque transmission during acceleration (the output power and torque are the largest, the torque waveform is large, and the impact on clutch components is also the largest).

\section{Comparison Of The Main Parameters Of The Damping Structure Of The New And Traditional Clutch Disc Assembly}


The main parameters of the wide-angle large damping multi-stage damping clutch driven disc assembly and the current domestic and foreign similar product technology are as follows:

1) The 200 series clutch product developed by adopting the new wide-angle large damping multi-stage damping clutch driven disc assembly technology (as shown in Figure 5), after inspection, the main performance parameters have reached the international advanced level of similar products, specific comparison data as shown in Table 1:

Table 1 Compares the main parameters of the current foreign similar technologies

\begin{tabular}{|c|c|c|c|c|}
\hline Test project & $\begin{array}{l}\text { Performance } \\
\text { Parameters } \\
\text { index }\end{array}$ & $\begin{array}{l}\text { Technical requirements of } \\
\text { drawing }\end{array}$ & $\begin{array}{l}\text { Performance of } \\
\text { this product }\end{array}$ & $\begin{array}{l}\text { International } \\
\text { Advanced } \\
\text { Product } \\
\text { Performance }\end{array}$ \\
\hline \multirow[t]{4}{*}{$\begin{array}{c}\text { Static torque } \\
\text { characteristics }\end{array}$} & $\begin{array}{c}\text { Pre- } \\
\text { damping } \\
\text { torsional } \\
\text { Angle } \square^{\circ}\end{array}$ & $5-22$ & 21.82 & 16.72 \\
\hline & 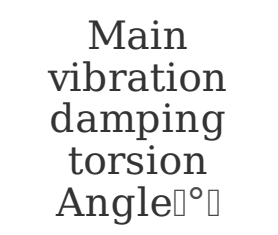 & $7-21$ & 20.21 & 15.76 \\
\hline & $\begin{array}{c}\text { Main } \\
\text { vibration } \\
\text { damping } \\
\text { value } ₫ \mathrm{Nm} \square\end{array}$ & $7-35$ & 32.37 & 25.63 \\
\hline & $\begin{array}{l}\text { Forward } \\
\text { transfer } \\
\text { torque } ₫ N m \square\end{array}$ & $190 \pm 20 \%$ & 198.72 & 189.78 \\
\hline Reliability test & $\begin{array}{c}\text { Torque } \\
\text { fatigue test }\end{array}$ & $\begin{array}{l}\text { Loading } 1.3 \text { times the } \\
\text { maximum torque of the } \\
\text { engine after } 1 \text { million } \\
\text { torsion tests without } \\
\text { component } \\
\text { deformation }\end{array}$ & $\begin{array}{l}3.5 \text { million torsion } \\
\text { tests } \quad \text { were } \\
\text { conducted } \\
\text { without } \\
\text { component } \\
\text { failure } \\
\text { deformation or }\end{array}$ & $\begin{array}{l}1 \text { million } \\
\text { torsion tests } \\
\text { without } \\
\text { component } \\
\text { failure, } \\
\text { deformation }\end{array}$ \\
\hline
\end{tabular}

2) Comparison of damping effect of the new wide-angle large damping multi-stage damping clutch driven disc assembly and the traditional clutch driven disc assembly

Wide-angle large damping multi-stage vibration reduction clutch driven plate assembly and traditional clutch driven plate assembly are respectively installed on a self-owned brand vehicle (the same vehicle). Muller-BBM vehicle torsional vibration/noise testing and analysis system is used to carry out NVH test for the vehicle, according to the test results (as shown in Figure 14 and Figure 15). 
From Figure 14 (left picture), after the engine (flywheel) speed is transmitted to one shaft of the gearbox through the traditional clutch, the fluctuation of the speed is amplified by more than 100RPM (the fluctuation of the speed of one shaft relative to the flywheel), and the amplitude of the gearbox is large, and the vehicle is prone to shake and abnormal sound; When the engine (flywheel) speed is transmitted to the first shaft of the gearbox through the wide-angle and large-damping multistage damping clutch at idle speed, the fluctuation of the speed is reduced to 30RPM (the fluctuation of the speed of the first shaft relative to the flywheel), and the amplitude of the gearbox is small, so the clutch has obvious damping effect. From Figure 15, when the speed of the engine (flywheel) is transmitted to the first shaft of the gearbox through the traditional clutch under the full acceleration condition of the second gear (left), the speed of the first shaft suddenly changes at the speed of 2738.94RPM, indicating that the transmission system has resonance at this speed; However, when the engine (flywheel) speed is transmitted to the first shaft of the gearbox through the traditional clutch under the full acceleration condition of the second gear (right figure), there is no obvious sudden change of speed, which indicates that the transmission system has no resonance in the speed range of 1000-4500RPM (engine speed range) in this gear. It shows that compared with the traditional clutch, wide-angle and large-hysteresis multi-stage damping clutch disc assembly can obviously improve the jitter and abnormal noise of the whole vehicle.

\section{Conclusions}

(1) Wide-angle and low stiffness vibration reduction technology is proposed. Through the design of large torsional vibration reduction angle and low torsional stiffness, better vibration reduction performance can be obtained. The torsional vibration reduction angle of this technology can reach 42 , and the vibration reduction effect is improved by more than 1.5 times compared with that of ordinary clutch. The maximum isolation rate can reach $65 \%$ in the engine $800 \mathrm{rpm}-4500 \mathrm{rpm}$ range.

(2) Put forward the technology of large hysteresis vibration reduction structure. By improving the material and structure of the clutch damping system, it has greater damping to meet the attenuation under severe working conditions, so as to reduce the resonance amplitude of the vehicle transmission system and improve the noise problem during the use of the vehicle.

(3) Propose a new split pre-vibration reduction structure technology. By making use of the injection molding process, which is easy to realize the complex modeling characteristics of the workpiece, the traditional damping sheet is improved, so that it has the function of damping sheet and clamping disc, which solves the shortcomings of the traditional split pre-vibration damping structure, such as complex structure, many parts, difficult assembly, low efficiency and high manufacturing cost. This technology can improve the production efficiency by over $150 \%$ and reduce the manufacturing cost by over $30 \%$.

(4) Put forward the structural technology of component protection, buffer and vibration reduction. By adding rubber buffer spring into the traditional clutch damping spring, the damping principle of rubber is used to absorb vibration and reduce noise when impact occurs, and the internal components of the clutch are protected. This technology is that when the engine torque fluctuates sharply when the automobile 
runs under severe working conditions, the rubber spring starts to work, and its torque capacity increases by $15 \%$ instantly, so as to absorb vibration and reduce noise and protect the internal components of the clutch, thus improving the service life of the clutch.

(5) Multi-stage vibration reduction technology is put forward, which can realize 3-6 stages of multi-stage vibration reduction combining clutch main vibration reduction and pre-vibration reduction by using a variety of vibration reduction spring combinations with different structures and stiffness and related designs, so as to meet the NVH performance requirements of vehicles under various working conditions.

(6) Wide-angle and large-hysteresis multi-stage damping clutch disc assembly series products can basically meet the requirements of most models in the market, and the vehicle performance is good. With the rapid development of automobile industry, especially the wide application of CVT and DCT transmission technology in China, higher requirements will be put forward for vibration and noise reduction (NVH). In order to meet these new demands in the market, it will be the future research and development direction of automobiles to study the clutch technology of pre-damping multi-stage damping mechanism and other structures such as main damping multi-stage damping structure based on wide-angle large hysteresis multi-stage damping technology.

\section{Declarations}

\section{Authors' contributions}

Maoqing XIE, methodology, investigation, validation, investigation, software, data collection, data analysis, data interpretation, writing-original draft and writing-review \&editing.

\section{Acknowledgements}

Supported by National Natural Science Foundation of China (Grant No. 51775249)

\section{Competing interests}

All the authors declare that they have no competing interests.

\section{Ethics approval and consent to participate}

Not applicable.

\section{Publisher's Note}

Springer Nature remains neutral with regard to jurisdictional claims in published maps and institutional affiliations.

\section{Biographical notes}


Maoqing Xie, born in 1974, Male, is currently a PhD student at School of Materials Science and Engineering, Jiangsu University, is currently a Senior Engineer at Zhejiang Tieliu Clutch Co., Ltd. His research interests include advanced manufacturing technology, new material technology, friction materials science and mold design and manufacturing.

Tel: +86-13606646047; E-mail: xmq@chinaclutch.com

Leigang Wang, born in 1963, Male, Zhenjiang, Jiangsu, Doctor, Doctoral supervisor. His research interests include CAD/CAE/CAM of mold, plastic processing tribology, and material mechanics behavior computer simulation.

Tel: +86-13646105959; E-mail: Igwang@ujs.edu.cn

Yao Huang, born in 1964, Female, Zhenjiang, Jiangsu, Master, Master's supervisor. Her research interests include CAD/CAE/CAM of mold, plastic processing tribology, and material mechanics behavior computer simulation.

Tel: +86-13646105921; E-mail: hywang@ujs.edu.cn

\section{References}

1. G Q Wu, W B Luan. Reviews of dynamic research for $\mathrm{NVH}$ problems related to automotive driveline[J]. Journal of Mechanical Engineering, 2013, 49凶24邓:108-116.

2. S Xu, F C Jiang. Automobile clutch. Beijing: Tsinghua University Press, 2005.8:130 135.

3. PRASAD J S, DAMODAR N C, NAIDU T S. Clutch hysteresis maximization for elimination of gear rattle in a passenger bus[R]. SAE Technical Paper, 2013-26-0100.

4. TSUJIUCHI N, KOIZUMI T, HARA N, et al. The effects of clutch damper in idling driveline rattle[C]//Topics in Nonlinear Dynamics, Volume 1: Proceeding of the 31st IMAC, A Conference on Structural Dynamics, 2013. Springer Science \& Business Media, 2013, 35: 259-267.

5. AGATE R, BADKAS A, MOHAN K. Driveline torsional analysis and parametric optimization for reducing driveline rattle[R] SAE 2015-01-2176, 2015.

6. Ivan SCANSANI GREGORI. Judder based on Sub Scale Test Machine Concerning Facing[J]. SAE Technical Paper Series, No.2013-01-1436.

7. WICKRAMARACHI P, Singh R, Bailey G. Analysis of friction-induced vibration leading to "EEK" noise in a dry friction clutch [J]. Noise Control Engineering Journal, 2005, 53₫4هष18-144.

8. Y H Chen. Test, analysis and evaluation of clutch jitter[D]. South China University of Technology, 2013.

9. W B Shang guan, T Sun, R Y Zheng, etc. Research on the Effect of Clutch Driven Disc Performance on Vehicle Starting Jitter [J]. Journal of Vibration Engineering, 2016, 29ه3هष488-497. 
10. W B Luan, G Q Wu. Starting simulation of automatic transmission based on 6-DOF drive train model [J]. Journal of Agricultural Machinery, 2013, 44囚4区凶1-7.

11. W B Yang, G Q Wu, Qin Datong. Modeling and shifting characteristics of dual-clutch automatic transmission system[J]. Journal of Mechanical Engineering. 2007, 43囚7هष188-194.

12. S Y Jing, G Q Wu, L J Wang. Analysis and Simulation of Vibration in Automatic Transmission Vehicles[J]. Automotive Engineering. 2013, 35ه8खष701-705.

13. H W Wu, G Q Wu, Xiang Chen, J W Wang, etc. Design and development and performance analysis of a new type of three-stage stiffness torsional vibration damper[J]. Journal of Mechanical Engineering, 2019, 55凶4凶:75-83.

14. X L Liu, W B Shang guan, Q F Hou, etc. Modeling and analysis method of friction clutch transmission system based on solving gearbox idling knock[J]. Journal of Mechanical Engineering. 2017凶4凶.

15. Fan Yu, Yi Lin. Automotive System Dynamics. Beijing: Mechanical Industry Press, 2005.7:130 134.

16. Z S Yu. Automobile Theory[M]. Beijing: China Machinery Industry Press, 2000.71 90.

17. J L Bi, J B Li, et al. Torsional mode and sensitivity analysis of power transmission system[J]. Chinese Journal of Vibration Engineering. 2010, 12:676-680.

\section{Figures}



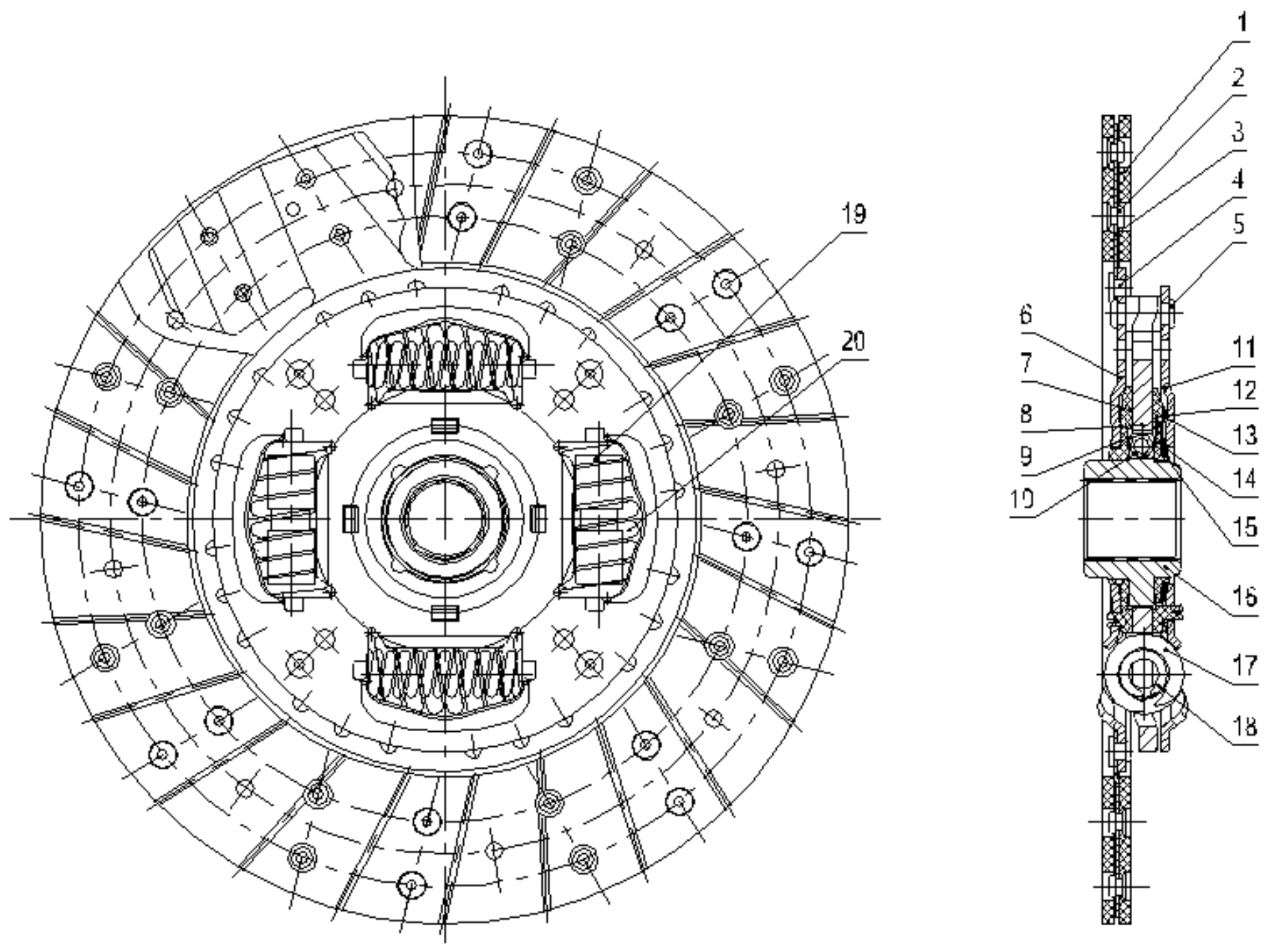

Figure 1

Structural drawing of traditional clutch disc plate assembly. 1. Friction facing 2. Friction facing rivet 3. Cushion segment 4. Cushion segment rivet 5. Stop pin 6. Driven plate 7. retain plate 8. Positioning ring (II) 9. Belleville washer (I) 10. Positioning ring (III) 11. Belleville washer (II) 12. Positioning ring (I) 13. Spring seat (I) 14. Spring (III) 15. Disc hub (I) 16. Disc hub (II) 17. Spring (I) 18. Spring (II) 19. Rubber spring 20. Spring (IV). 

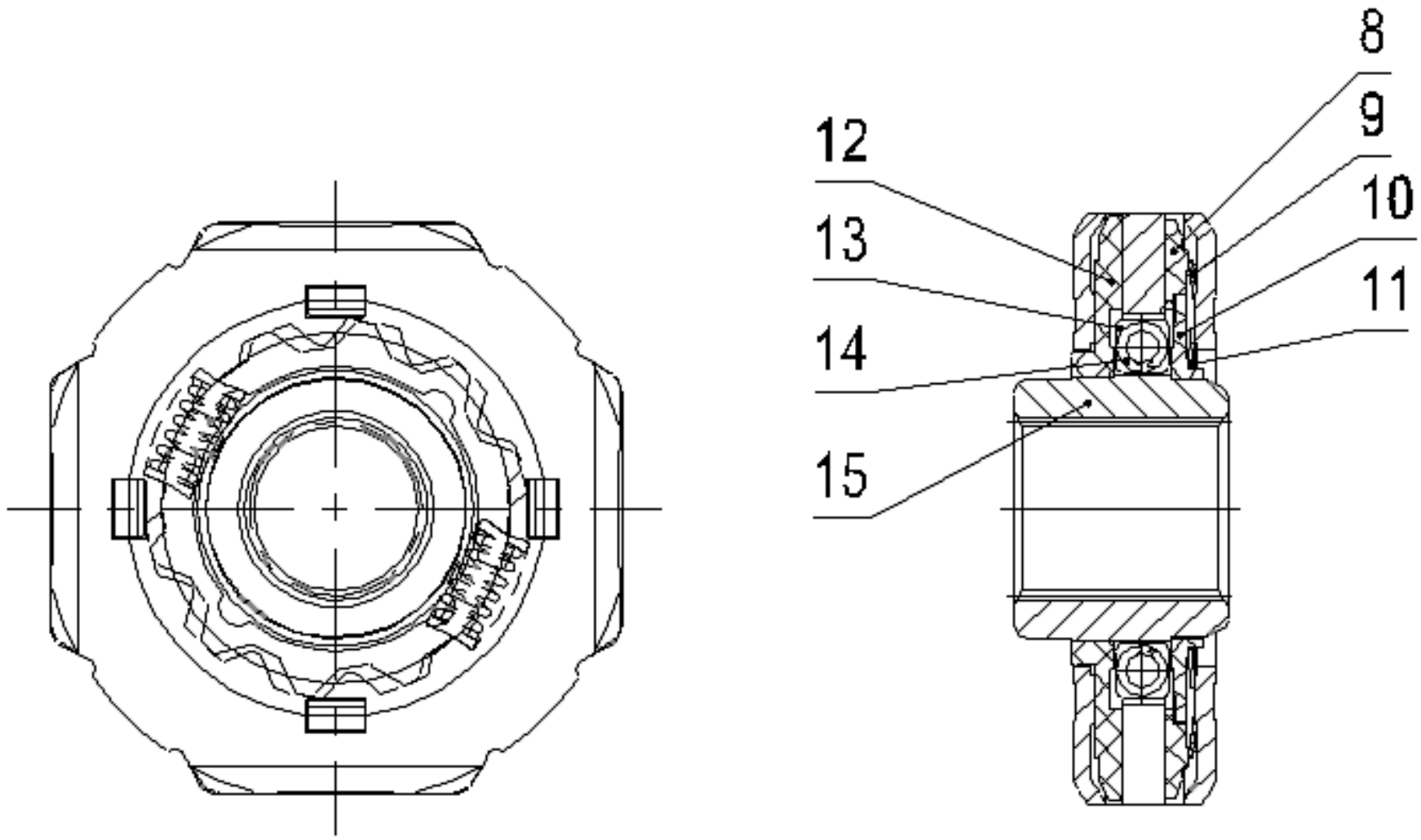

Figure 2

Structure diagram of idle damping system of traditional clutch driven disc assembly. 8. Positioning ring (II) 9. Belleville washer (I) 10. Positioning ring (III) 11. Belleville washer (II) 12. Positioning ring (I) 13. Spring seat (I) 14. Spring (III) 15. Disc hub (I) 

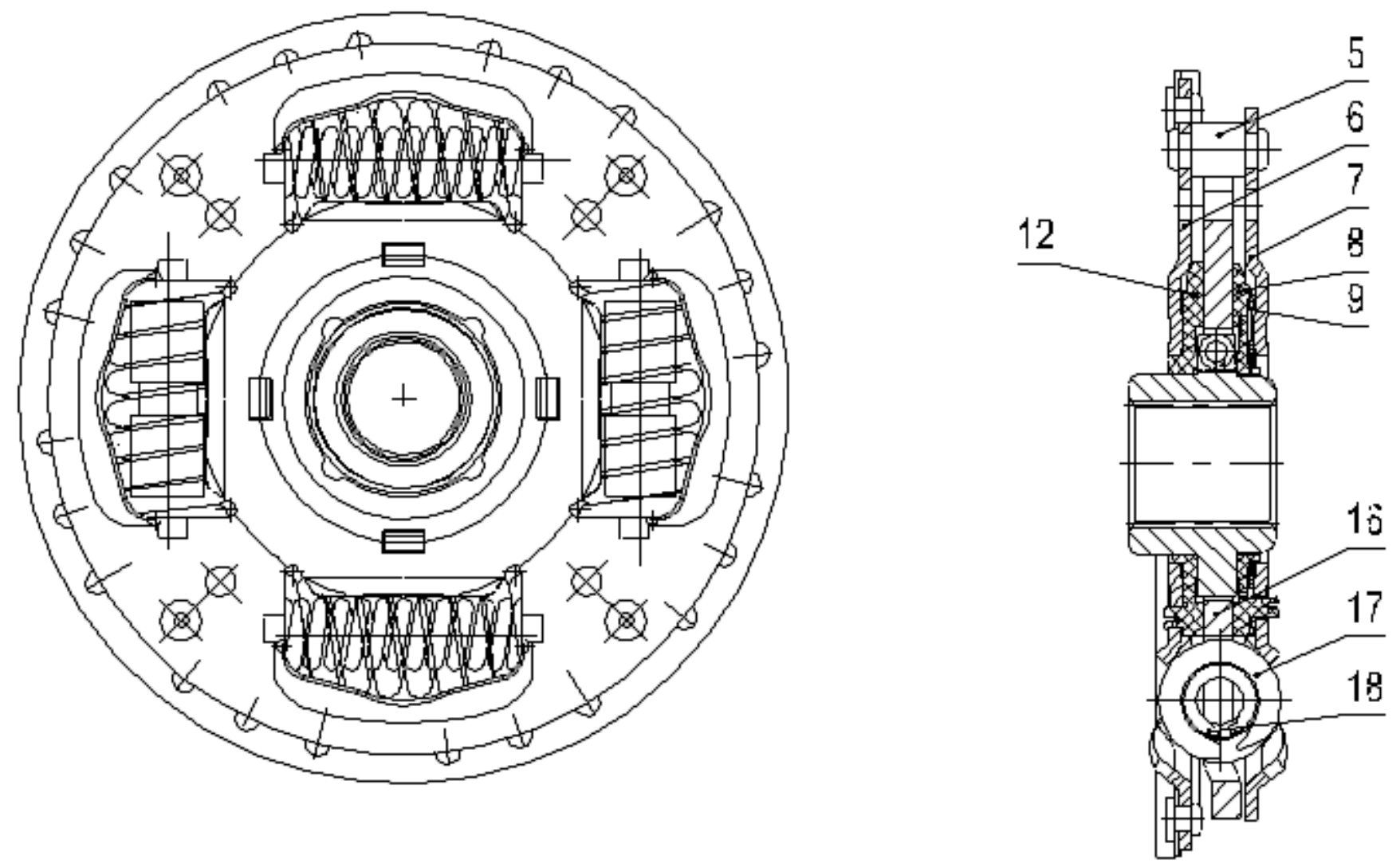

Figure 3

Structure diagram of main damping system of the traditional clutch driven disc assembly. 5. Stop pin 6 . Driven plate 7. Retain plate 8. Positioning ring (II) 9. Belleville washer (I) 12. Positioning ring (I) 16. Disc hub (II) 17. Spring (I) 18 .Spring (II) 


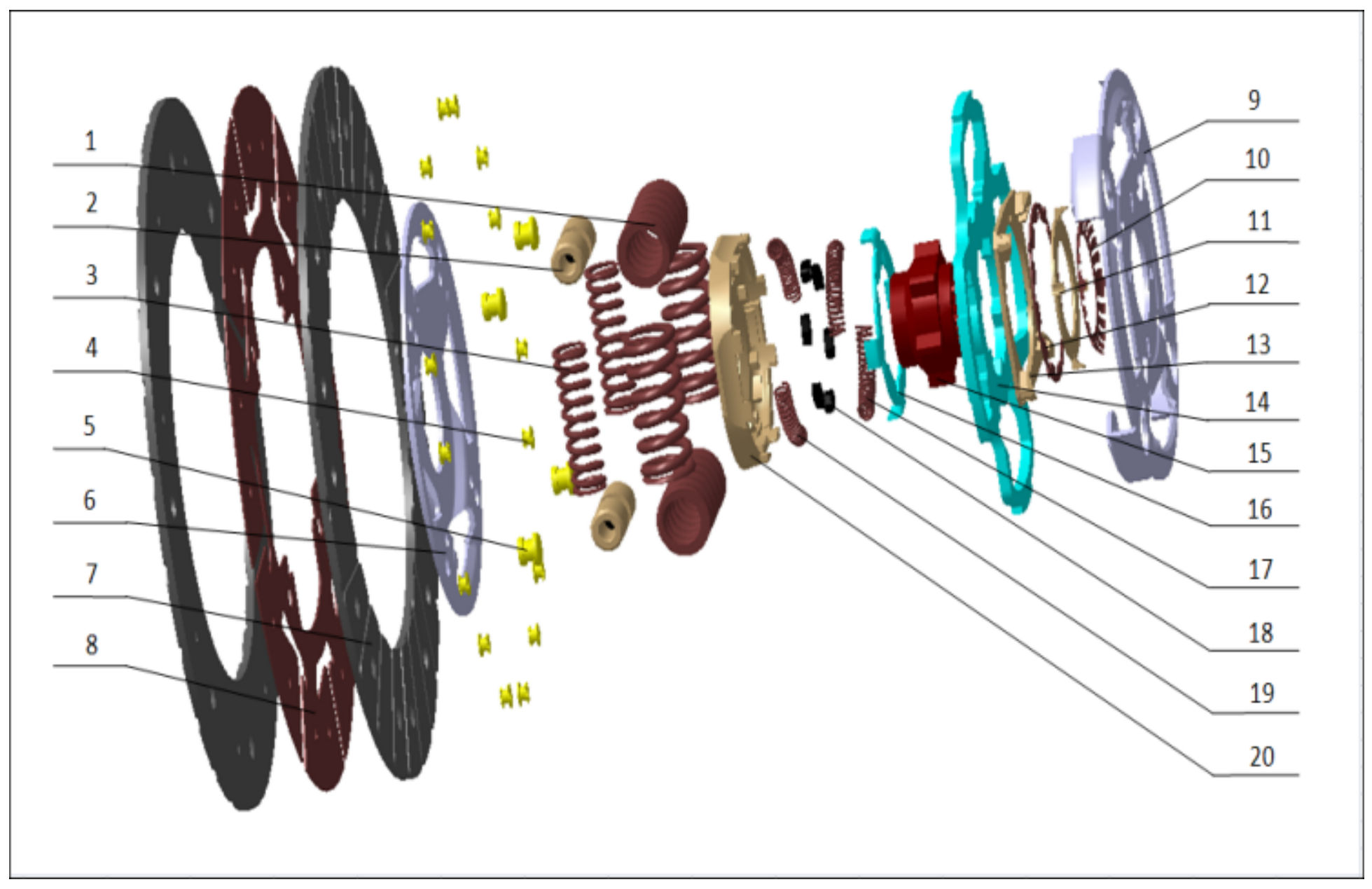

\section{Figure 4}

Structure diagram of driven disc assembly of wide-angle large damping multi-stage damping clutch. 1 . Main damping spring (outside) 2. Rubber buffer spring 3. Main damping spring (inside) 4. Friction facing rivet 5. Damping disc rivet 6. Rear retain plate 7. Friction facing 8. Cushion plate 9. Front retain plate 10. Pre-damping Belleville washer 11. Pre-damping damping plate 12. Main damping Belleville washer 13. Main damping plate 14. Hub plate 15. Hub 16. Pre-damping disc hub 17. First-level pre-damping spring 18. Cushioning rubber pad 19. Second-level pre-damping spring 20. Rear damper plate 


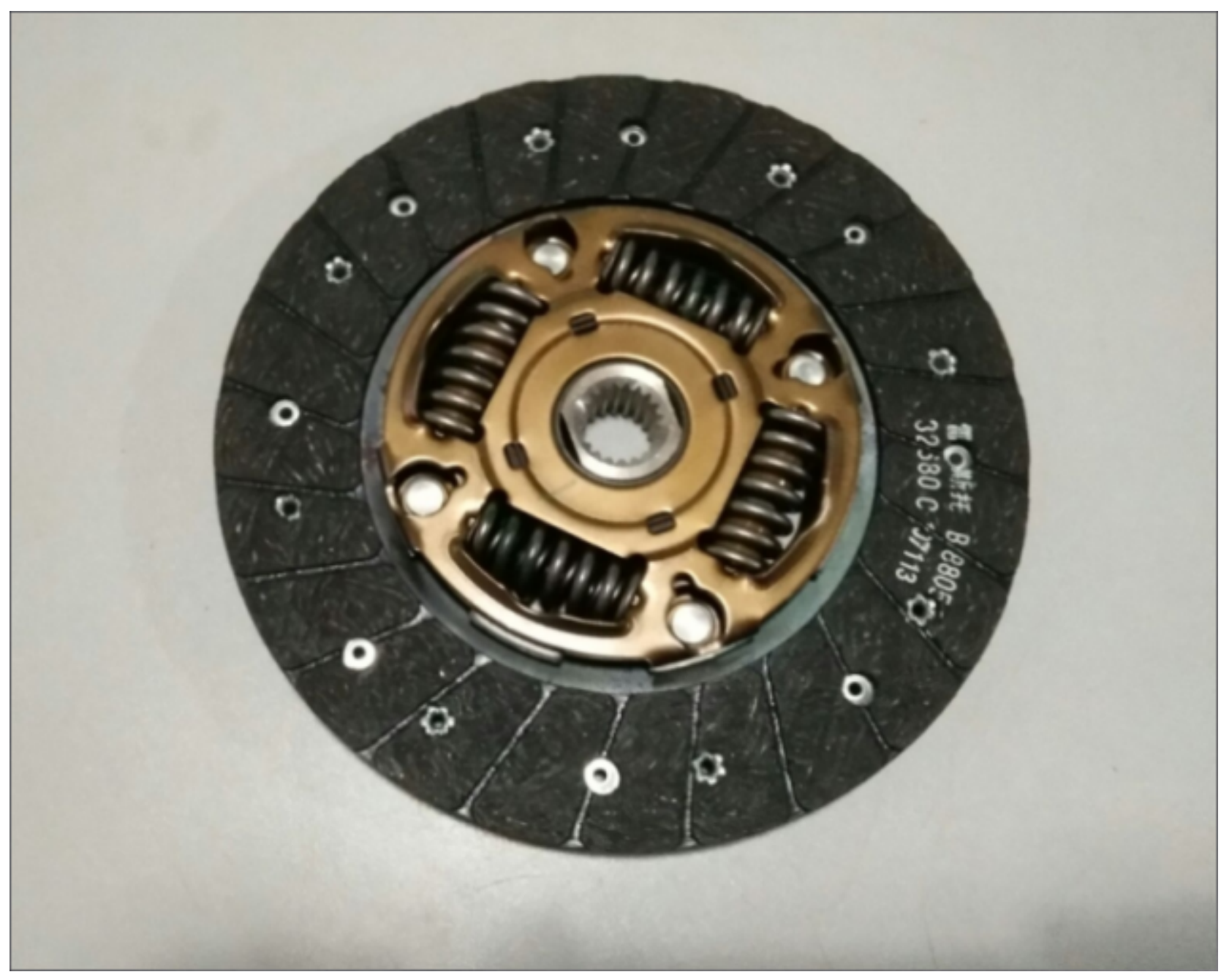

Figure 5

The physical picture of a wide-angle large-damping multi-stage damping clutch product

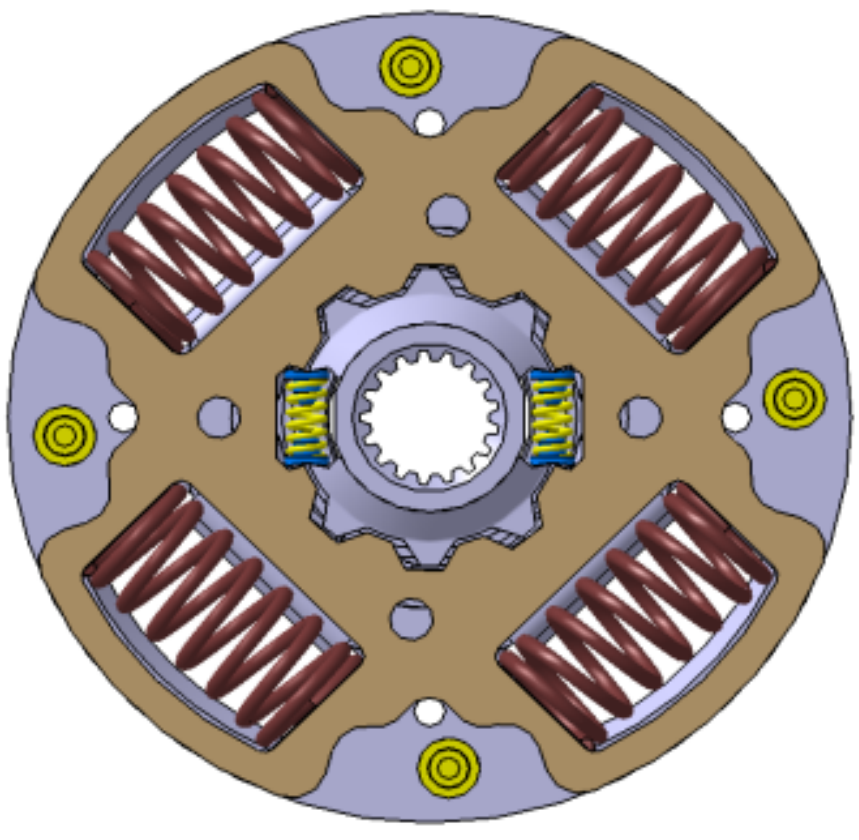


Figure 6

Schematic diagram of internal structure of traditional clutch

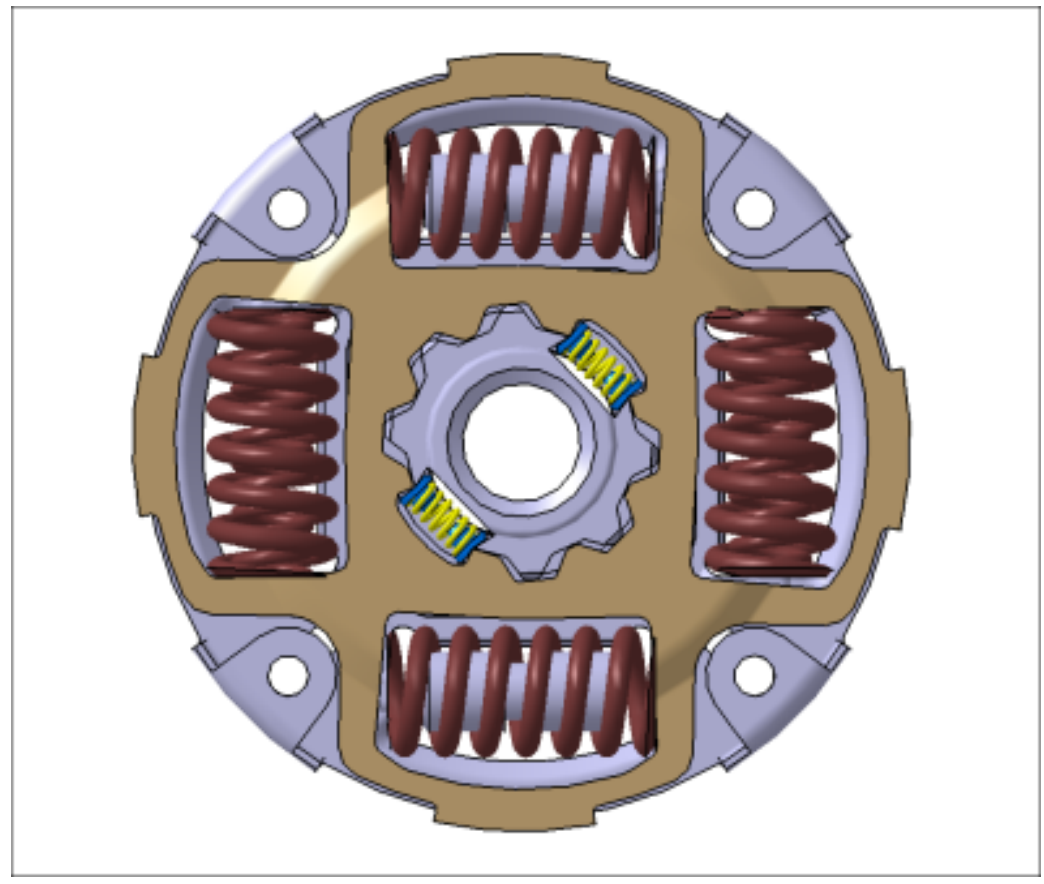

Figure 7

Schematic diagram of internal structure of low-stiffness clutch

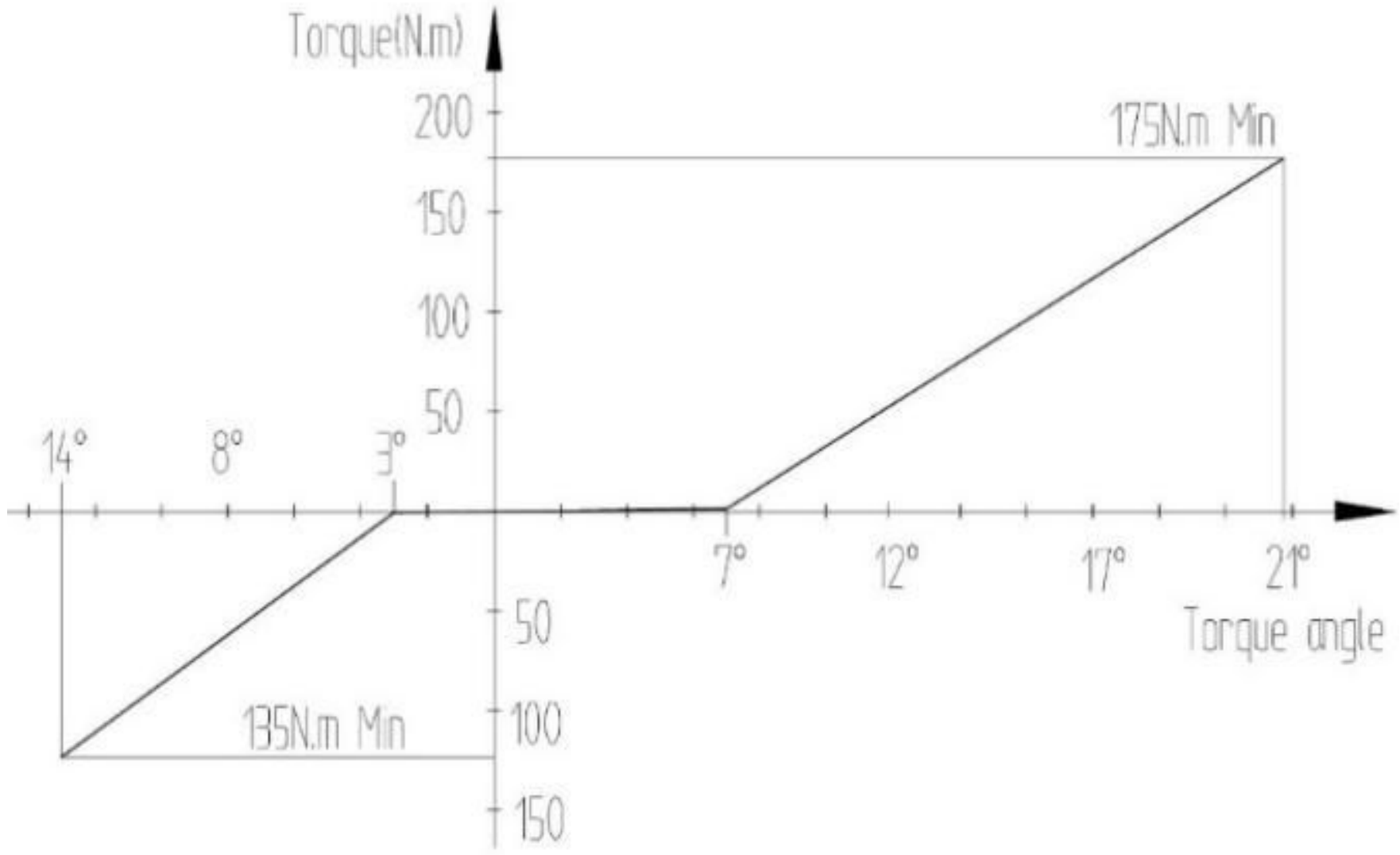

Figure 8 
Schematic diagram of traditional clutch torsional performance

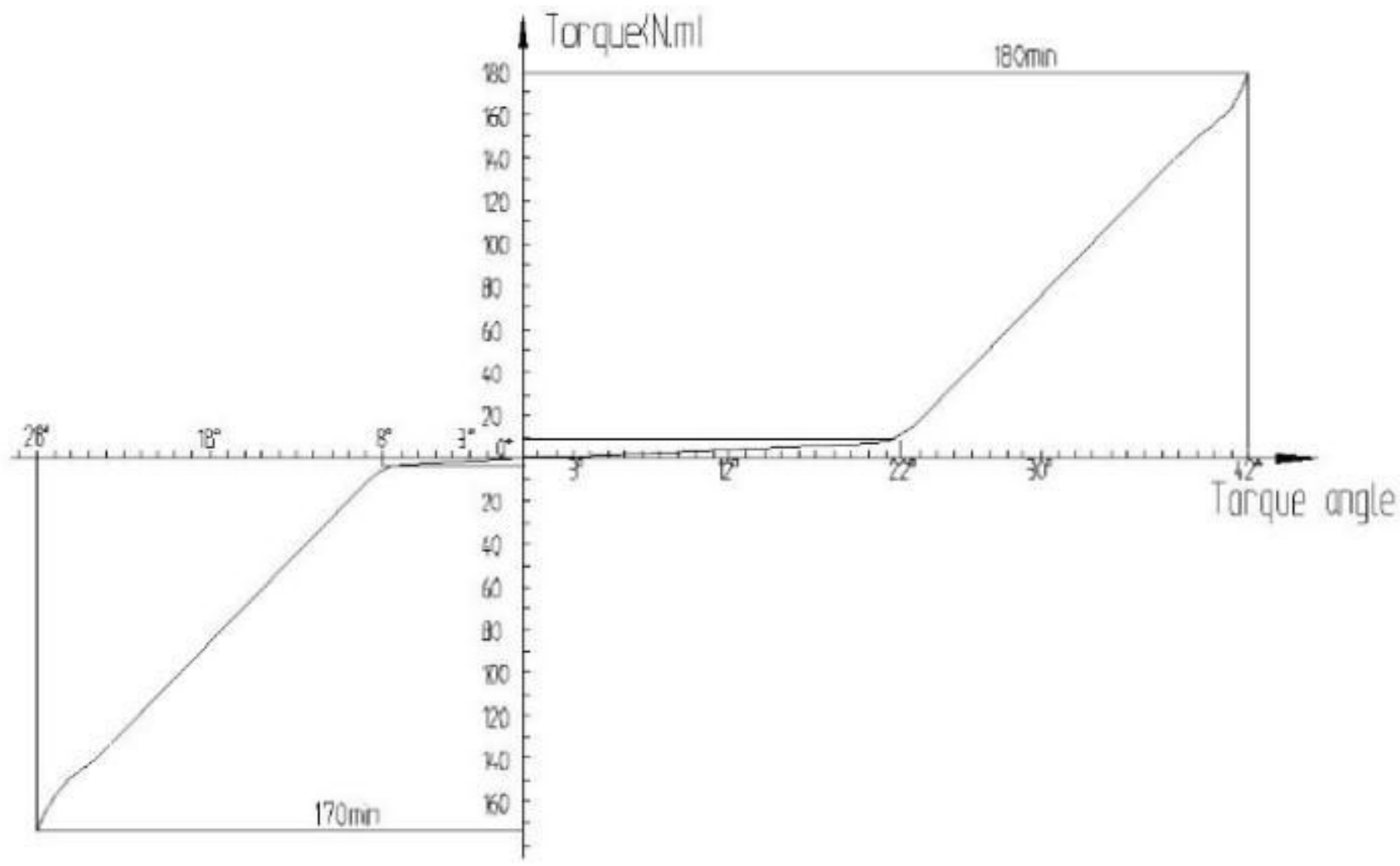

Figure 9

Schematic diagram of low-degree clutch torsional performance

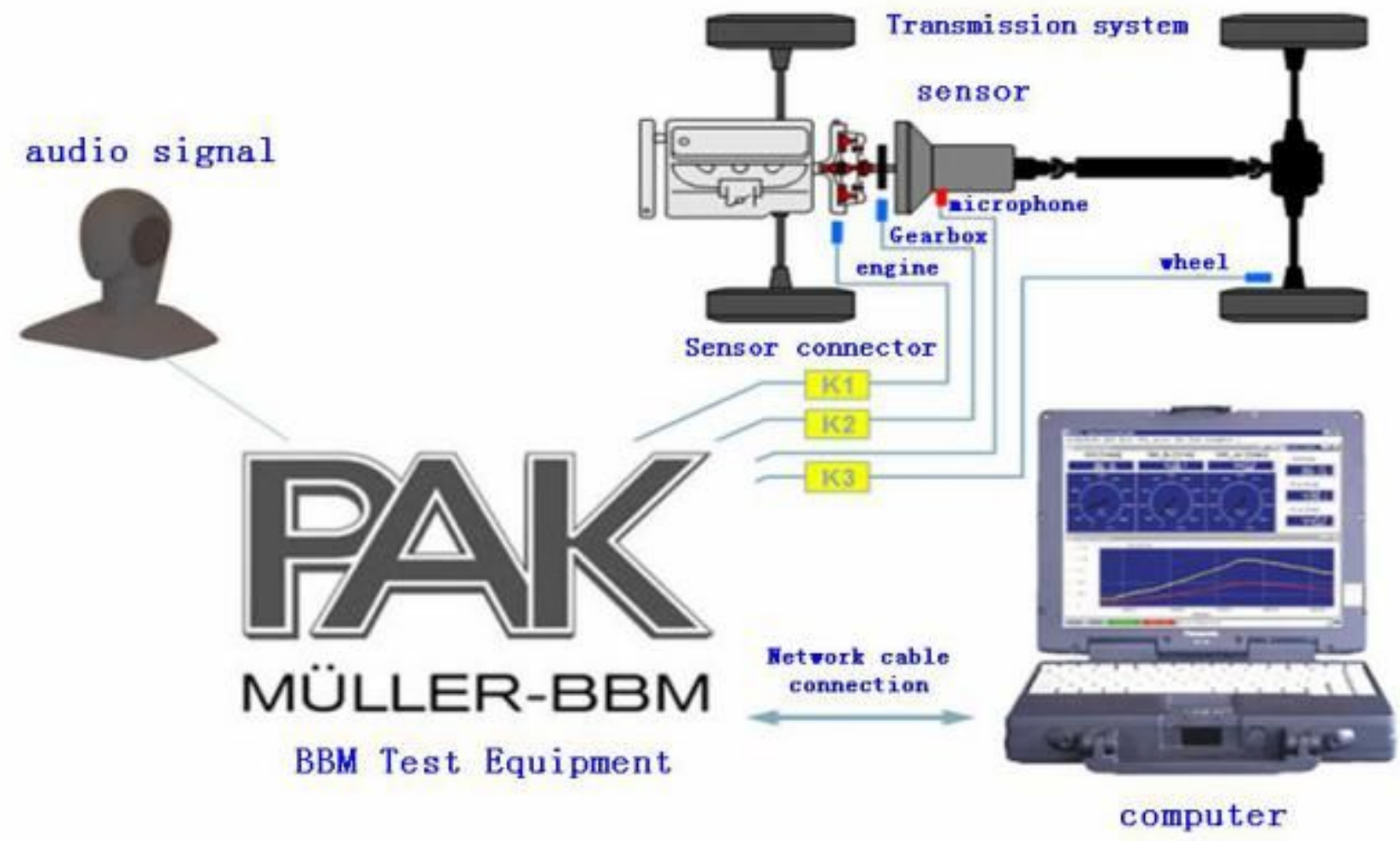


Figure 10

Vehicle torsional vibration/noise testing and analysis system

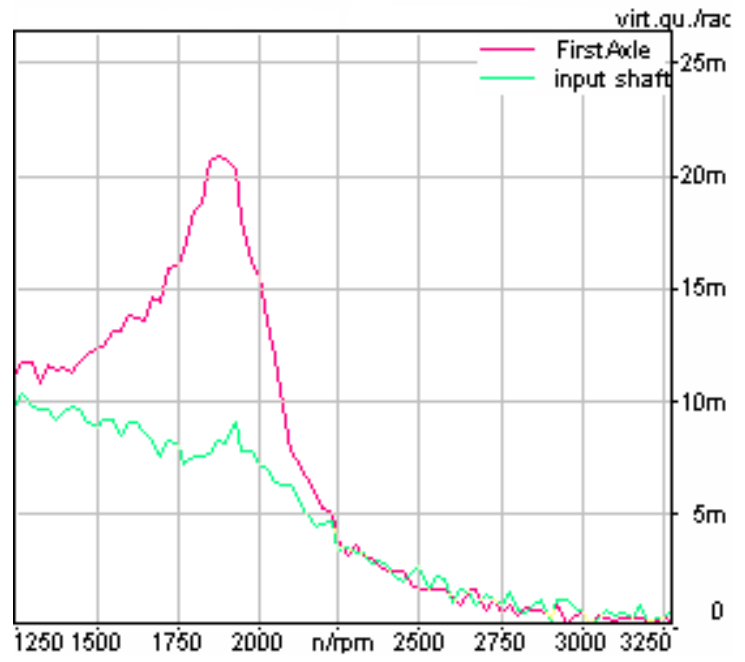

\section{Figure 11}

Comparison test results of 3rd gear acceleration torsional vibration
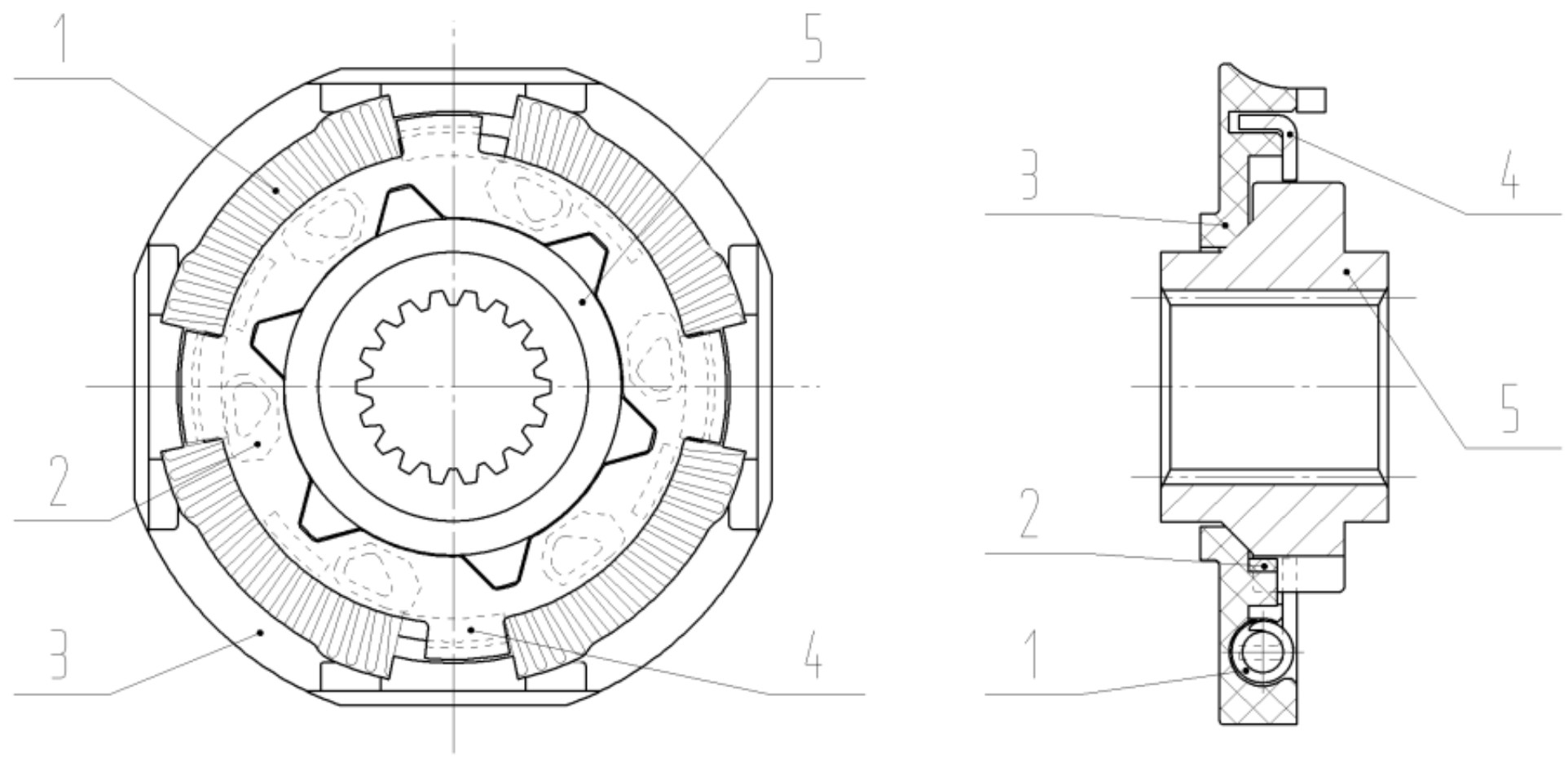

Figure 12

Schematic diagram of the new split pre-vibration structure. 1. Pre-damping spring 2. Rubber pad 3. Rear damping plate 4. Pre-damping disc hub plate 5. Hub 


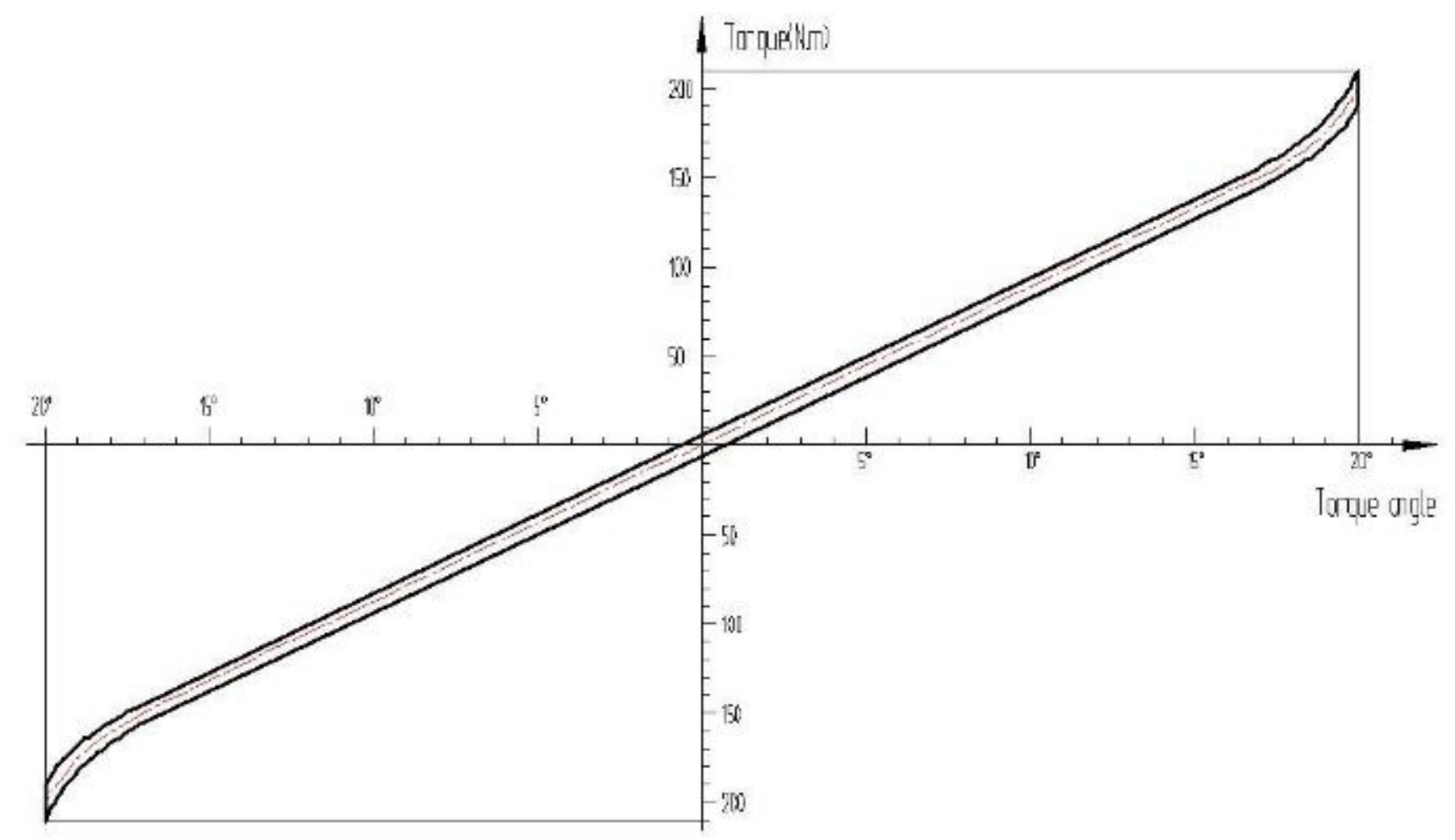

Figure 13

Characteristic curve of clutch equipped with buffer spring group

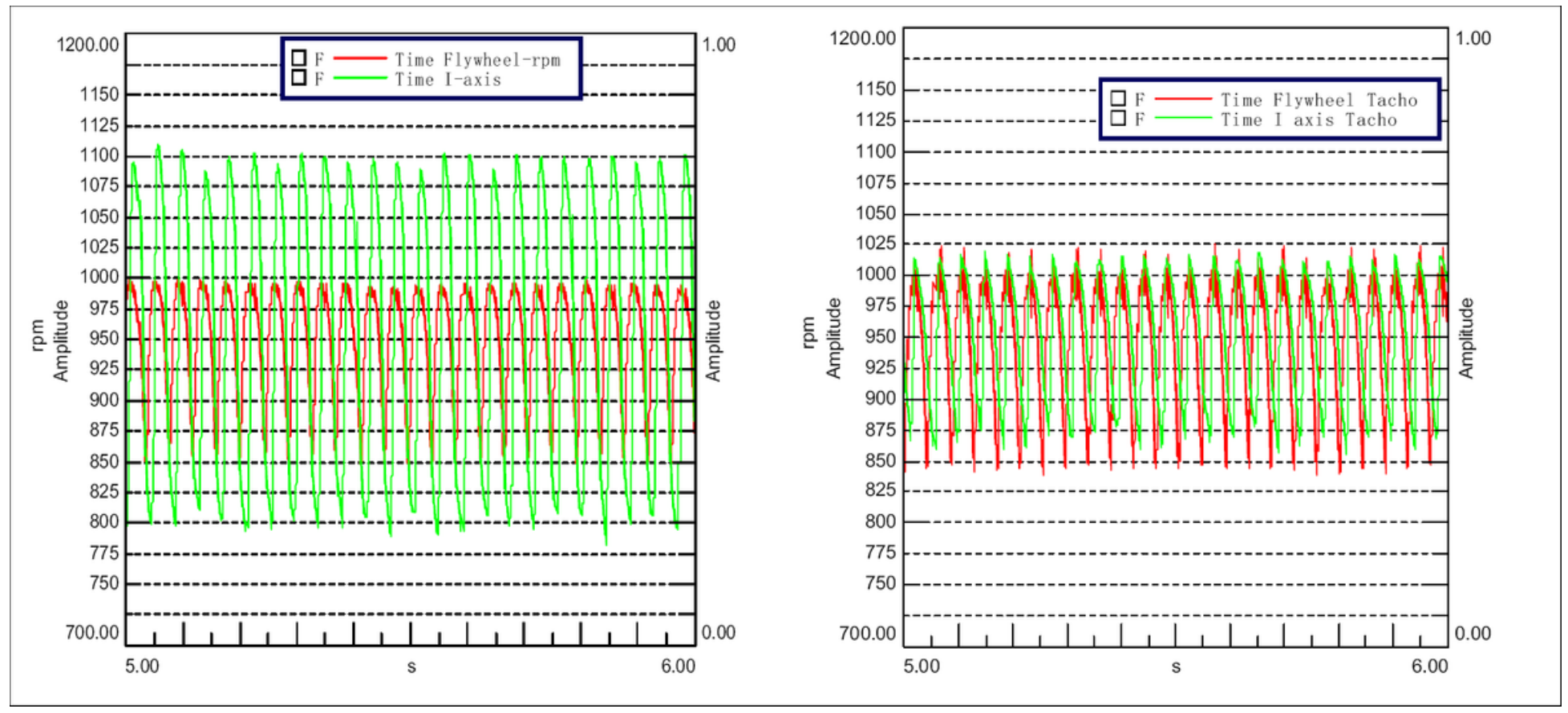

\section{Figure 14}

Flywheel and a shaft speed fluctuation in idle condition (traditional clutch on the left and multi-stage wide-angle damping clutch on the right) 


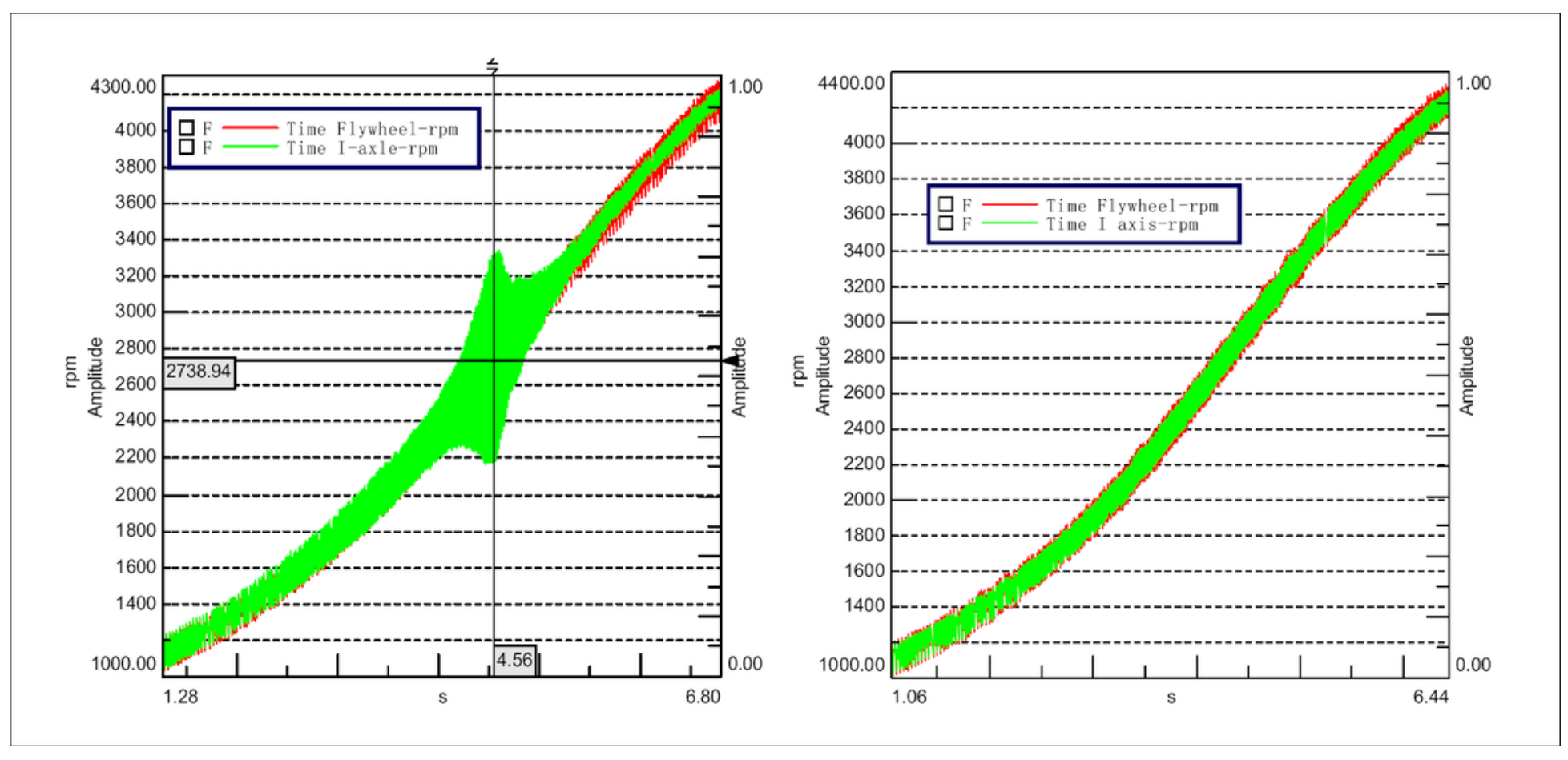

\section{Figure 15}

Speed fluctuation of flywheel and input shaft of gearbox under full acceleration condition of second gear (left is traditional clutch, on the right is the multi-stage damping clutch with wide rotation angle and large damping) 